\title{
Addressing seasonal transport demand in touristic areas through public transport interventions
}

\author{
M. Morfoulaki ${ }^{1}$, Y. Tyrinopoulos ${ }^{1}$, K. Kotoula ${ }^{2}$, \\ G. Myrovali ${ }^{1} \&$ N. Georgantis ${ }^{3}$ \\ ${ }^{1}$ Hellenic Institute of Transport, Greece \\ ${ }^{2}$ Technological Institute of Athens, \\ Hellenic Institute of Transport, Greece \\ ${ }^{3}$ Planning, Organization and Informatics Office, \\ Kos Municipality, Greece
}

\begin{abstract}
The aim of this paper is to propose a new scheme for the reorganization of a public transport system in order to cover seasonal demand. The scope of the paper is to enhance the use of the public transport system and to minimize the use of private cars. The island of Kos is one of the Greek islands that hosts every summer more than 1,000,000 visitors. The permanent habitants of the island are 35,000 and most of them live in the capital of the island, the city of Kos. There are two operators providing public transport services. KEAS, which is a Municipal Company for running public transport services within the city of Kos and KTEL Kos SA, which provides public transport services, outside the urban area of the island. The new legal framework - KALLIKRATIS program applied in 2011 to the Municipalities - led to the consolidation of municipalities on the island, creating the appropriate conditions for the integration of its public transport services. The seasonality of the public transport demand creates a lot of problems to the existing system as it cannot cover the seasonal needs during summer but it also provides low operational characteristics during winter. The result of this situation is the system is not trusted by the users and the modal share of the private car has reached $80 \%$.The main objective of the current work is to present a prototype methodology for the optimization of the services that the public transport system provides to the residents and visitors of the island of Kos.
\end{abstract}


The proposed methodology is taking into account the need for the existence of high quality public transportation services and aims to achieve: adequate road network coverage for the satisfaction of all passengers (residents of urban areas, rural residents, visitors, students, etc.), sustainability for all public transport providers and flexible management framework which allows future adaptation of alternative public transport systems and supports the economic development of the island.

Keywords: public transport systems.

\section{Introduction}

\subsection{The problem}

Shugan and Radas [1] argued that seasonality is a phenomenon that has impacts to nearly every product and service, while Jang [2] argued that seasonality could be defined as a cyclical pattern that more or less repeats itself periodically. Shugan and Radas [1] supported that the impact of this phenomenon to the providers of these services or products is particularly important because they are often unable to adapt to seasonal changes in demand through traditional methods. Soesilo and Mings [3] argued that for many firms, the seasonality of demand constraints profitability, while for others it may determine their viability. Consequently, understanding and adjusting services or products to seasonality of demand dominate many of the decisions made by managers.

The transport sector is an example of varying or seasonal demand that is largely affected due to predictable or unpredictable variations in demand of other industry sectors overtime. Such variations in demand for transport services are observed in touristic areas during high seasons caused by the variations in demand of the touristic industry. Such regions include islands, lakesides, mountainous regions, regions of archaeological interest, coastal areas, etc.

Robertson et al. [4] argued that seasonality in the transport sector has various and very important effects, some of which are congestion in the major transport routes, damage of the transport infrastructure, severe environmental pollution, energy loss, increased travel times, damage to the natural environment, low quality services provided to the visitors and harms to the historical sites.

Therefore, the effective handling of seasonal traffic peaks is essential so as to avoid the decrease in tourism in these areas and therefore to maintain the high income deriving from the touristic sector.

\subsection{Aims of the paper}

The aim of this paper is to propose a new Methodological Framework that can be used by touristic regions in order to effectively address the seasonal transport demand problems and their severe effects. This Framework is based on the improvement of local public transport through appropriate operational and organizational interventions. The Framework has been successfully applied in one of the most touristic islands of Greece, Kos. In this paper, a short outline of 
the Framework is presented, however particular emphasis is placed on its application in Kos Island. A discussion is followed on the benefits that can be drawn from the adoption of the Framework for various target groups (tourists, local community etc.).

\section{Methodological framework for addressing the seasonal transport demand problem}

\subsection{Setting the criteria}

The main objective of this Framework is to set the principles, terms and actions that will allow the local authorities to create a sustainable transport system, the basis of which will be public transport. In this respect, the criteria that need to be respected are:

- Strong participatory approach engaging all types of local stakeholders (authorities, chambers of commerce, touristic businesses, transport operators)

- Establishing of links between public transport and other modes and means (e.g. taxi, bicycling etc.)

- Addressing the needs of not only tourists but also residents in order to enable the viability of the system during off-season periods

- Setting a flexible organizational and management scheme allowing future adaptations of alternative public transport systems and other mobility measures

- Supporting the economic development of the touristic region by ensuring accessibility to remote areas and facilitation of commerce.

\subsection{The main axes of the Framework}

The proposed Framework includes a series of actions that are grouped in the following axes:

- Assessment of the local transportation system

Before proposing any kind of intervention, it is necessary to evaluate the local transportation environment. This entails the local transport operators (bus, taxi, ports, airport etc.) as well as possible intermodal services, infrastructures, lines and other characteristics.

- Identification of the needs and priorities of target groups

This axis includes an identification of all target groups that either affect or are affected by the establishment of a sustainable transportation system. These include: tourists, residents, local businesses, transport operators etc. The next step is to perform a sound understanding of their needs and priorities, through questionnaire surveys, and engage them in fruitful discussion that will facilitate the development of a well-organized transport system. 
- Analysis of organizational, legislative and financial barriers

In many cases, the existence of organizational, legislative and financial barriers prevents the adoption of solutions that could provide the answer to the seasonal transport demand problem. These need to be identified and thoroughly analysed in order to display and adopt the appropriate solutions.

\section{- Use of relevant research products/knowledge}

Pisano [5] found studies shown that policy makers use scientific knowledge very sporadically and on occasional basis when they feel the necessity to answer some questions or when they have to deal with urgent and immediate issues. Gjoksi [6] argued that they generally use scientific knowledge for making decisions and for conceptual tasks either when they have to think 'strategically' or when they are in the phase of development of policies. Ward et al. [7] argued that since knowledge brokerage is not only concerned about knowledge transfer from researchers to policy makers, there is an imperative need to provide the responsible decision makers in touristic areas with the suitable tools and information that will facilitate the selection and establishment of sustainable interfaces among existing transport modes, as well as efficient and economically, viable measures for the satisfaction of the ever increasing transport demand. Mitsakis et al. [8] found that one such research result that can be very useful for local authorities in touristic areas are the DELTA DSI, a tool that was developed under the project DELTA aiming to assist local transport and other agencies of regions with seasonal varying transport demand profiles in the selection of the most appropriate, in each case, mobility scheme (or combination of schemes) in order to manage this demand in a sustainable way.

\section{- $(R e) D e s i g n$ and implementation of transportation system}

Based on the above actions, the new or upgraded transportation system will be designed and implemented. This system will address the needs of the various target groups and will take into account financial opportunities, strong participation of stakeholders and available research products. The backbone of this system will be the transit services encouraging a strong modal shift from other modes towards public transport.

\section{- Post implementation actions}

The success of the new transportation system will largely depend on the adoption of actions, such as awareness campaigns, monitoring of the performance of the system and frequent meetings among the various local stakeholders.

\section{Case study}

\subsection{Study area}

Kos island is located in the South East Aegean Sea in Greece and is one of the most popular Greek destinations for European mainly tourists. In 2011, Kos was visited by more than 1.1 million tourists. 5\% of these tourists were Greeks, 70\% 
originated from the rest EU member states, while the rest $25 \%$ outside the EU. It has a population of close to 31,000 residents and a surface area of $287.2 \mathrm{~km}^{2}$. The peak season in Kos includes July, August and September. These three months account for $71 \%$ of the tourists visiting the island throughout the entire year.

The car ownership index for the residents accounts for approximately 13,000 cars. There are two bus public transport operators in Kos, the Municipal bus transit operator and the interurban bus operator. The first serves the city centre and the surrounding areas, while the second the rest of the island. Cycling, public transport and coach are the dominant modes used by tourists. Especially cycling is extensively used by tourists, since Kos has one of the most attractive and well organized cycling infrastructures in Greece, containing $28 \mathrm{~km}$ of two-lane cycling network connecting many hotels and resorts with well-known poles of attraction, such as beaches, archaeological sites etc. The cycling infrastructure also includes parking stations at terminals, signalizing pathways and bicycle rental services. It is also very encouraging the fact that the local residents are becoming more and more familiar of this mean, as they directly see the benefits of using it. Therefore, a high priority of the local authorities is to further expand the cycling network and develop additional forms of mobility based on this network, such as bike sharing. This policy is strengthened by the high traffic congestion especially in the peak period taking into account that the average mileage travelled annually only by rental cars is approx. 55 million km.

\subsection{Overview of the seasonal demand problem in the site}

The island of Kos has special characteristics regarding seasonality and high variation on trip demand. Monthly trips range from 750,000 during winter to 2.3 million during summer, due to visitors arriving to the island from May to October (approximately 1,000,000 people). The peak season in Kos is between July $15^{\text {th }}$ and August $15^{\text {th }}$.

The above needs could be covered, by a flexible transport system providing quality services to both residents and visitors. For residents this transport system would be an opportunity to reduce the increased use of private car while for visitors would be an opportunity to plan and complete their trips reliably.

Trips during summer are mostly carried out by tourist buses (45\%), servicing visitor groups mainly, while the respective percentage of private car is $22 \%$. Public Transport trips account for $8 \%$ of the total trips in Kos, while no more than $1 \%$ of the trips are conducted by taxis.

On the other hand, the vast majority of trips during winter, are conducted with private cars (90\%), with Public Transport and taxi being relatively rarely used ( $0.5 \%-0.3 \%$ respectively).

Reasons for the above percentages vary. Both in summer and winter, the capacity of the Public Transport System, does not cover more than 30\% of the daily demand. If this number is reduced to peak hours it will not exceed $20 \%$. This inevitably makes the system unreliable. Schedule frequencies as well as road network coverage does not allow the existing transport system be an alternative solution replacing bus or private car. 


\subsection{Assessment of the local transportation system}

According Kos’ PT System Master Plan Project [9], there are two operators providing public transport services in Kos Island. KEAS, which is a Municipal Company for running public transport services within the city of Kos and KTEL Kos SA, which provides public transport services, outside the urban area of the island.

KEAS fleet consists of seven buses with a capacity of 100 people serving four out of six lines, and three mini buses with a capacity of 45-50 people serving the other two.

KTEL Kos SA fleet consists of fifteen buses, running the predefined routes. During the school year, the company also runs itineraries serving school transportation. KTEL Kos is also responsible for providing additional services (for example if various bus routes are particularly busy).

Besides those two operators, public transport services are being carried out by private taxis. Their fleet has a total of seventy vehicles.

During the winter period, KEAS runs 63 itineraries and KTEL Kos 17.

The perspective numbers during the summer period are 193 for KEAS and 65 for KTEL Kos SA.

Regarding the road network coverage as well as the itineraries' adequacy and following a careful analysis of the data collected concerning KEAS and KTEL Kos SA schedules, some conclusions are presented below:

1. KTEL Kos SA only provides a transportation line serving Kos airport a few times within a day. There should be an increase in schedules to/from the airport so as the whole island is served.

2. There is no bus service connecting the port of Kos with the terminal stations of KEA and KTEL. Visitors reaching Kos by sea can only reach the city by a taxi or alternatively, they need to walk to the terminal, covering a distance of 200 to 600 meters (depending on the terminal station).

3. The Terminal station's location should be reconsidered as it negatively affects traffic, increasing traffic volumes and trips' distance.

4. The villages of Mastichari and Kardamena are being used for the transition of both residents and visitors to/from Kalymnos and Nisyros islands. The provided bus services in that case is insufficient and the residents and visitors of these two islands are not being served satisfactorily.

The need for a possible change in the transport system of the island is obvious considering:

- The above conclusions about the quality of the services provided

- The passengers' traffic analysis between KEAS and KTEL Kos SA.

- The new administrative structure, according to which all municipalities of Kos were joined in one and therefore there is no clear separation of the urban and interurban services provided. 


\subsection{The needs and priorities of the target groups}

According Kos' PT System Master Plan Project [10], the record of users' opinion (visitors and residents) held through a survey questionnaire concerning both users traveling by KEAS and KTEL Kos SA. The questions included in the questionnaire related to trip characteristics between the terminal station and various destinations. The survey was conducted for a period of seven days during the summer period. Totally, 827 questionnaires were completed (202 concerning long-distance trips and 625 urban trips). The sample is statistically significant, and therefore useful conclusions and overall trends can be conducted. Figure 1 depicts trips characteristics of visitors participated in the survey.

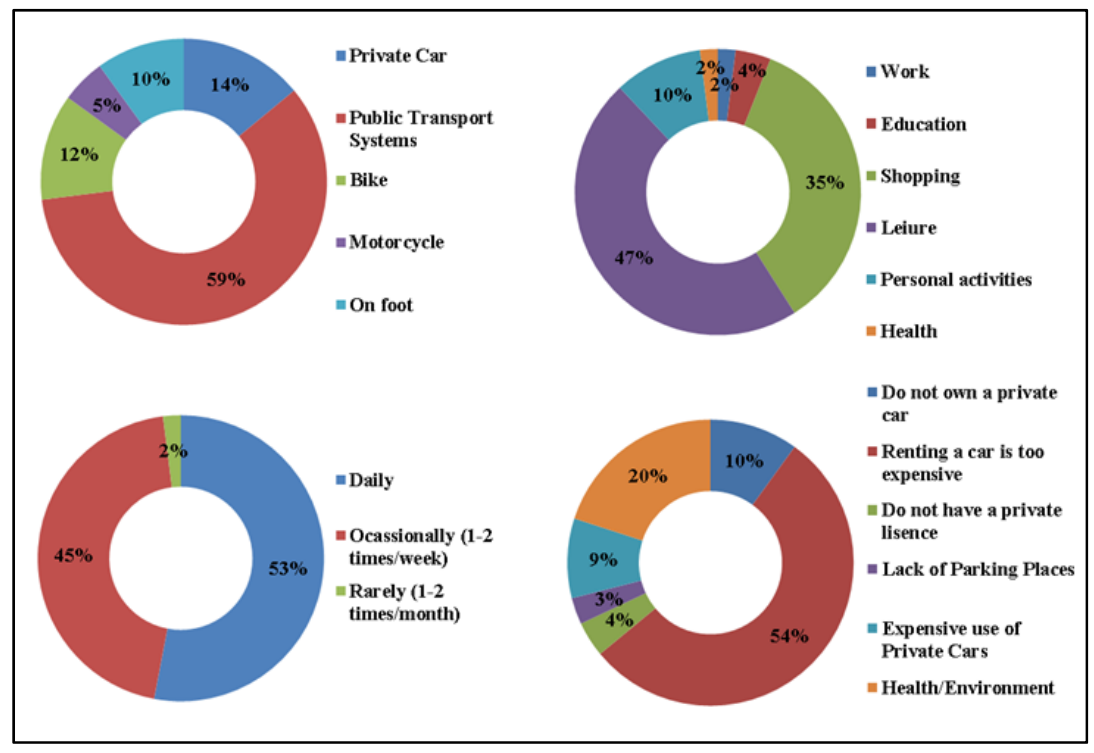

Figure 1: $\quad$ Basic trip characteristics of visitors.

In the last part of the questionnaire a quadrant analysis was conducted concerning twenty-three qualitative factors of Kos public transport system. Quadrant analysis is based on the respondents' judgment concerning the importance and assessment of key factors determining the operation of a public transport system. The rating scale ranges between 1(very low) to 5(very high)

The quadrant analysis revealed some basic problems in the quality offered. Due to the different functionality characteristics of KEAS and KTEL Kos SA, the systems were examined separately.

KTEL seems to have some problems, especially in terms of road network coverage and infrastructure's quality (stops, information systems, number of vehicles). Problems are more often during the winter period when itineraries are 
reduced by $75 \%$, making it very difficult to move from various suburban areas of the island to the town of Kos.

The overall analysis proves the substantial differentiation of the quality offered between summer and winter period. There is a dense frequency system during summer and a less adequate system during winter. The above issue seems to be even more intense in areas outside the capital where KTEL Kos SA operates.

The main conclusion from the quadrant analysis is that there is an imperative need to develop a system that will meet residents' needs during the winter period with the same reliability and efficiency that seems to cover the summer period.

Another key finding is that information for schedules is insufficient and particularly in KTEL Kos SA where there is only one time table given to the passengers concerning the scheduled trips. Therefore, there is an immediate need for strengthening the information services, by introducing upgraded innovation systems.

\subsection{The proposed transit system}

The main objectives of a public transport system is the development and maintenance of a high quality and reliability network, adequate services in the urban area and attraction of Private Car users, which reduce congestion, pollution and energy consumption and contribute to the system's financial viability. To achieve these objectives, the system should have:

- Characteristics based on seasonal demand

- Appropriate routing

- Reliability

- Capabilities of transit systems

- Synchronized transit systems

- Adequate infrastructure

- Acceptable cost for users

- Better road network coverage

The reorganization of Kos public transport system should be based on the above principles. Particular emphasis should be given on the first principle, as the proposed system should adequately cover summer season's needs and also be maintained during the winter. To achieve this, the proposed system should be attractive and therefore it will be used by more residents, ensuring that way its financial viability.

According to these, the island was divided beyond the urban area into three different zones. In suburban area, short distance interurban and long distance interurban area. The zones' boundaries are depicted in Figure 1 below. 


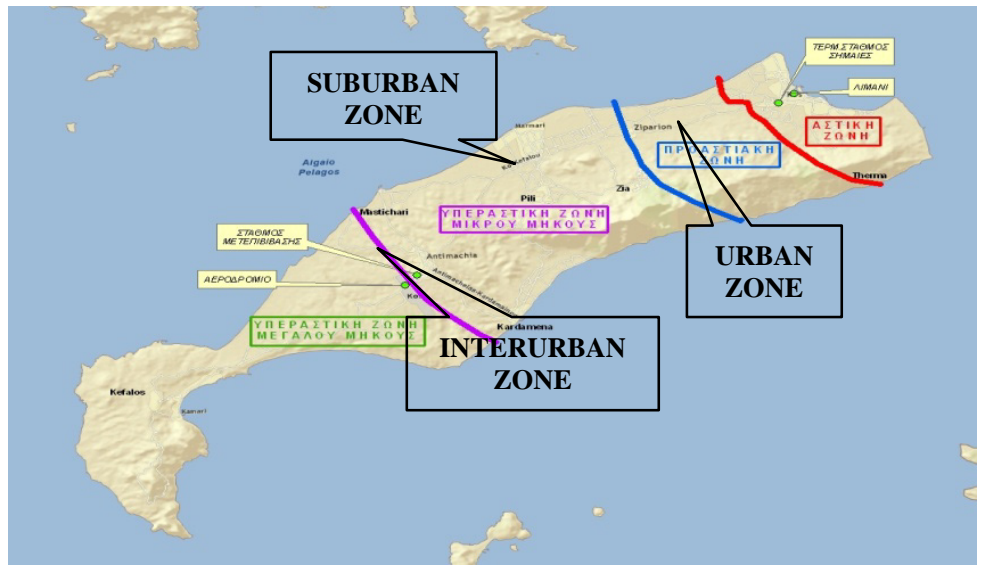

Figure 2: $\quad$ The proposed zones of Kos public transport system.

According to the planning, the urban area of the island, includes the town center, where the highest population density and most land uses are concentrated. Furthermore, it extends along the coast to the western and eastern parts of the island enclosing several tourist destinations located close to the center. During the summer period, this area attracts large percentage of visitors and residents. For this reason it is proposed to be served by short length bus lines, in the form of a radial network. The routes are not linear as in a classic hub network but cyclical. Only two of these extend linearly.

It is proposed that the other zones are served by long length bus lines. More specifically, the zone which extends to the village Zipari is characterized as suburban zone. Zipari has a population of 2.500 residents and it's only nine kilometers away from the city center. Many citizens of Kos Island have their permanent residences in the village. For this reason and due to the nature of the road network of the island, all long length bus lines go through this village.

The short length interurban zone extends to the Kos airport, where a terminal installation is proposed. That way, many distant destinations become more attractive and intra-community trips are made more easily. The connection between public transport bus lines through the terminal, enhances accessibility to the airport and meets the needs of visitors mainly for immediate arrival or departure to and from the airport Kos.

The long distance interurban zone extends beyond the airport and connects Kefalos, the most remote village of the island, both with other villages through the terminal and with the urban and suburban zones through the other bus lines.

The new proposed plan includes seven short distance lines and twelve long distance lines. The short distance lines run 147 daily itineraries in winter and 327 in summer. Long distance lines run 41 daily itineraries in the winter and 196 in the summer. There are also extra long distance lines proposed for students' transfer. These lines are designed in order to fully meet students' needs. The 
planning solves essentially the basic problem of the variation on demand between summer and winter.

As most of the movements of visitors are made by private buses - the creation of a single entity that will join the fleet of all the operators (tourist, KEA, KTEL) and will enhance the frequency of service throughout the year, mainly on long distance lines makes the system attractive to both visitors and resident.

Finally, for the services' quality that seems to be a severe problem for the users, upgraded information systems are proposed to be installed within and outside the vehicle. Moreover, reliable and comprehensive information can be provided through the internet while terminals and stops should be redesigned.

\section{Conclusions}

Seasonal public transport demand is considered as a severe issue for the tourist areas of Greece and especially the islands. Trips are multiplying during the summer period. The operators who provide public transport services are required to cover this variation by increasing P.T. trips during the peak period. Public transport's winter profile is totally different. As the demand is very low, the frequency is reduced over $50 \%$ and the P.T. system becomes unreliable. Therefore, its use considered prohibited for the residents, making the financial sustainability of the system more difficult.

The proposed solution follows a specific framework of actions, which assess the current system using user's opinions, creates new organizational structure with strong cooperation of all the relative authorities and finally design a new or upgraded transportation system.

In conclusion, two are the main advantages of the proposed system:

1. The synergy of all the transport providers in order to create a united organization for the achievement of a common vision (development of a single entity accounting a large number of fleet and manpower)

2. The creation of an attractive public transport system- also for the residents- in order to serve the financial viability of the system during off-peak tourist period (reallocation of terminals, increase of frequency, upgrade of the services' quality).

\section{References}

[1] Shugan, S. M. and Radas, S., Services and Seasonal Demand, Handbook of Services Marketing and Management, T. A. Swartz and Iacobucci (Eds.), Sage Publications, pp. 147-170, 1999.

[2] Jang, S., Mitigating Tourism Seasonality - A quantitative approach, Annals of Tourism Research, Vol.31, No 4, pp. 819-836, 2004.

[3] Soesilo, J. A., and Mings, R. C., Assessing the Seasonality of Tourism, Visions in Leisure and Business, Vol. 6, No.2, pp. 25-38, 1987.

[4] Robertson, K., R. Karlsson, A. Kortsari, and Y. Tyrinopoulos, Knowledge Base of regions with seasonal varying demand profiles, Deliverable D2.3 of the DELTA project, 2009, www.delta-project.eu. 
[5] Pisano U. on behalf of the CORPUS Consortium, Knowledge management of transport policy-makers and their interaction with researchers Summary of the interviews with policy-makers for 1st Policy Meets Research on sustainable mobility, COPRUS Project, 2011.

[6] Gjoski, N., Knowledge management of sustainable development policymakers and their interaction with researchers, CORPUS project, 2010.

[7] Ward, V., A. House and Hamer S., Knowledge brokering: the missing link in the evidence to action chain, Evidence and Policy 5 (3), pp. 267-279, 2010.

[8] Mitsakis, E., Robertson, K., Galdi, E., Massa, G., Kortsari, A. and Tyrinopoulos Y., Final (validated) Decision Support Instrument, Deliverable D4.2 of the DELTA project, 2010, www.delta-project.eu.

[9] Morfoulaki M, Kotoula K, Iordanopoulos P., Analysis of KOS' Current Public Transport System, Deliverable D1 of the KOS’ P.T. System Master Plan Project, 2011.

[10] Morfoulaki M, Kotoula K, Operational Analysis of the KOS' Proposed Public Transport System, Deliverable D2 of the KOS' P.T. System Master Plan Project, 2011. 